\title{
SURFACE ARTHROPLASTY FOR TREATING PRIMARY AND/OR SECONDARY SHOULDER OSTEOARTHROSIS BY MEANS OF THE HEMICAP-ARTHROSURFACE ${ }^{\circledR}$ SYSTEM
}

Adalberto Visco', Luis Alfredo Gómez Vieira², Felipe Borges Gonçalves ${ }^{3}$, Luis Filipe Daneu Fernandes ${ }^{4}$, Murilo Cunha Rafael dos Santos ${ }^{5}$, Nivaldo Souza Cardozo Filho ${ }^{6}$, Nicolas Gerardo Gómez Cordero ${ }^{7}$

\section{ABSTRACT}

Objective: To present the surgical technique for the HemiCAP-Arthrosurface ${ }^{\circledR}$ system and evaluate our results from this technique for treating primary and/or secondary shoulder osteoarthrosis. Method: Between June 2007 and June 2009, 10 shoulders of 10 patients (nine with primary osteoarthrosis and one with avascular necrosis of the humeral head) underwent surface arthroplasty using the HemiCAP-Arthrosurface ${ }^{\circledR}$ system to correct the problem. The follow-up time ranged from six to 29 months (mean of 17 months). The patients' ages ranged from 62 to 73 years (mean of 67.5 years). Six patients were female and four patients were male. The patients were followed up weekly for the first month after the surgical procedure and every three months thereafter. The clinic evaluation was done using the criteria of the University of California at Los Angeles (UCLA) and a visual analogue pain scale. Results: All the patients said that they were satisfied with the results from the surgical treatment, with a mean UCLA score of 30 points and a mean analogue pain score of two points. Conclusion: The HemiCAP-Arthrosurface ${ }^{\circledR}$ system for shoulder surgery for a specific group of patients is a technique that preserves the bone stock with good functional and antalgic results.

Keywords - Shoulder/pathology; Arthroplasty/methods; Osteoarthritiss

\section{INTRODUCTION}

Shoulder arthroplasty was first presented by Neer for treating proximal fractures of the humerus ${ }^{(1)}$. However, the most frequent indication for shoulder arthroplasty in non-traumatic cases is osteoarthrosis ${ }^{(2-5)}$. Degenerative abnormalities of the shoulder are associated with incapacitating pain and decreased range of motion. Thus, the aims in treating this condition include diminishing the pain and improving function ${ }^{(6)}$.

The design of Neer's prosthesis was very similar to what is widely used for hip arthroplasty. However, it was seen that using a humeral nail/component was unnecessary if the tuberosities were intact ${ }^{(7)}$.

Considering this idea, some authors sought to develop a type of arthroplasty using resurfacing for treating degenerative pathological conditions of the shoulder ${ }^{(8-10)}$. The design of this type of prosthesis is based on the principle of minimum bone resection. This theoretically has the advantage of preserving the bone stock by reconstructing the normal joint geometry ${ }^{(11,12)}$.

1 - Head of the Shoulder and Elbow Surgery Group, ORTOPED Fracture Clinic; Member of the Shoulder and Elbow Surgery Group of Bahia.

2 - Coordinator of the Shoulder and Elbow Surgery Group, CATO Traumatological and Orthopedic Accident Victim Clinic; Member of the Shoulder and Elbow Surgery Group of Bahia.

3 - Sixth-year Medical Student at the Bahia School of Medicine and Public Health.

4 - Attending Physician in the Shoulder and Elbow Surgery Groups, CATO and ORTOPED Clinics; Member of the Shoulder and Elbow Surgery Group of Bahia.

5- Attending Physician in the Shoulder and Elbow Surgery Groups, CATO and ORTOPED Clinics; Member of the Shoulder and Elbow Surgery Group of Bahia.

6 - Attending Physician in the Shoulder and Elbow Surgery Groups, CATO and ORTOPED Clinics; Member of the Shoulder and Elbow Surgery Group of Bahia.

7 - Orthopedic Surgeon at the Portuguese Hospital of Bahia. 
The aim of the present study was to present our experience from treating patients with mild to moderate stages of primary and/or secondary osteoarthrosis of the shoulder by means of the HemiCAP-Arthrosurface $^{\circledR}$ system. This method restores the congruence of the humeral head, preserves the remaining healthy joint surface and preserves the bone stock of the proximal humerus.

\section{METHODS}

Between June 2007 and June 2009, ten shoulders from ten patients were treated surgically using the HemiCAP-Arthrosurface ${ }^{\circledR}$ system: nine patients because of osteoarthrosis and one patient because of avascular necrosis of the humeral head. The procedures were performed by the Shoulder and Elbow Group of the CATO Traumatological and Orthopedic Accident Victim Clinic and were evaluated after approval from the institution's ethics committee.

The length of follow-up ranged from six to 29 months, with a mean of 17 months. The patients' mean age was 67.5 years, with a range from 62 to 73 years. Six patients were female and four were male (Table 1).

The patients were sent for physiotherapy procedures and were released for activities of daily living as soon as possible, according to their pain threshold. The importance of early mobility was emphasized, while respecting the reinsertion of the subscapular tendon with limitation on external rotation to the neutral position during the first four weeks. The patients were followed up every week for the first month, every month for the first three months and every three months after the fourth postoperative month.

The method chosen for clinically assessing the patients during the postoperative period was based on the UCLA criteria (University of California at Los Angeles) ${ }^{(13)}$, and on an analogue pain scale and a questionnaire on patients' degree of satisfaction after the operation (Table 1).

\section{SURGICAL TECHNIQUE}

The surgery was performed in all cases with the patient in a "deckchair" position, under general anesthesia and plexus block.

We started the procedure through a deltopectoral access, opened in layers. After moving the cephalic
Table 1 - Data on patients.

\begin{tabular}{c|c|c|c|c}
\hline $\begin{array}{c}\text { Patient } \\
\text { number }\end{array}$ & Sex & $\begin{array}{c}\text { Preoperative } \\
\text { analogue } \\
\text { scale }\end{array}$ & $\begin{array}{c}\text { UCLA } \\
\text { (preoperative) }\end{array}$ & $\begin{array}{c}\text { Postoperative } \\
\text { follow-up } \\
\text { (months) }\end{array}$ \\
\hline 1 & Female & 9 & 7 & 29 \\
\hline 2 & Female & 10 & 8 & 27 \\
\hline 3 & Male & 8 & 12 & 24 \\
\hline 4 & Male & 10 & 6 & 22 \\
\hline 5 & Female & 10 & 7 & 17 \\
\hline 6 & Female & 10 & 5 & 15 \\
\hline 7 & Male & 8 & 12 & 20 \\
\hline 8 & Female & 10 & 8 & 17 \\
\hline 9 & Male & 8 & 8 & 6 \\
\hline 10 & Female & 10 & 7 & \\
\hline Source: DOT-CATO & \multicolumn{5}{l}{} \\
UCLA = University of California at Los Angeles - method for assessing postoperative results.
\end{tabular}

vein and conjoined tendon away laterally and medially, respectively, we made a longitudinal incision in the upper two-thirds of the tendon of the subscapular muscle and the anterior joint capsule.

After making a dislocation maneuver on the humeral head, we identified the proximal degenerative disease of the humerus (Figure 1). Then, after resecting all the osteophytes surrounding the humeral head, we started the resurface procedure using the HemiCAP-Arthrosurface ${ }^{\circledR}$ system.

The normal axis of the joint surface was located and the defect in the humeral head was centralized by means of a Kirschner metal wire, using a specific guide. Then, a hole was drilled in the proximal humerus using a cannulated bit (Figure 2).

The metal wire was kept in the origin position and a threaded pin was inserted. This would then receive the implant, which was previously measured using a specific measuring device. Next, a circumferential rasp was coupled, which would prepare the bed for the final implant (Figures 3 and 4).

We then checked the specific number of the implant by means of a test piece, and after this, we inserted the final prosthesis (Figures 5 and 6).

Finally, the surgical wound was closed in layers after emplacing a suction drain (3.2), followed by a compressive dressing. A control X-ray image was produced (Figure 7). The repair on the subscapular tendon, which was a fundamental structure for the quality of the clinical results, was done using transosseous sutures in the lesser tuberosity. It should be emphasized that balancing the soft tissues in order to restore physiological movement was of fundamental importance for the final result from the surgical procedure. 


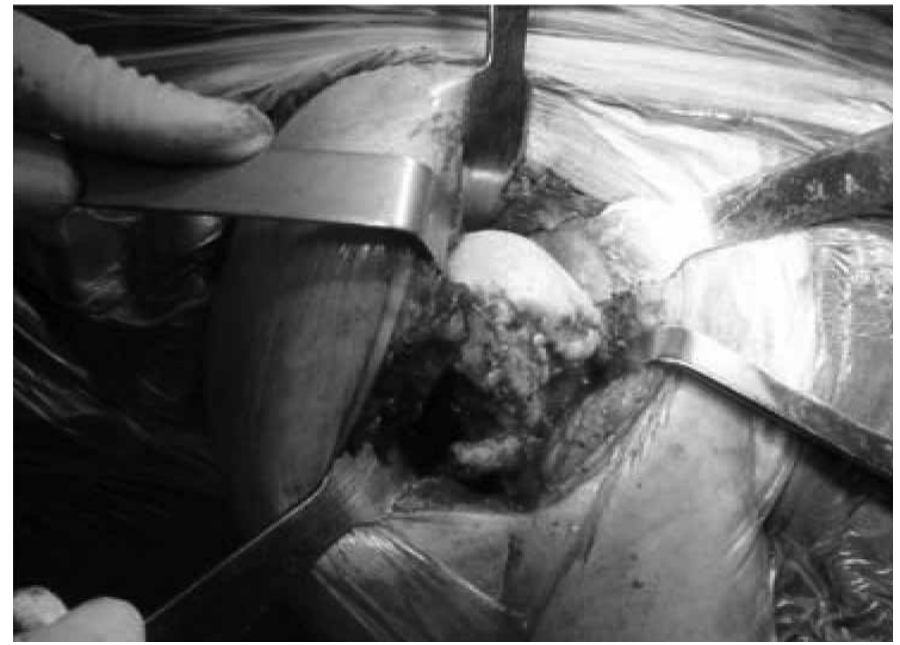

Figure 1 - Degenerative pathological condition in the proximal humerus seen after dislocation maneuver.

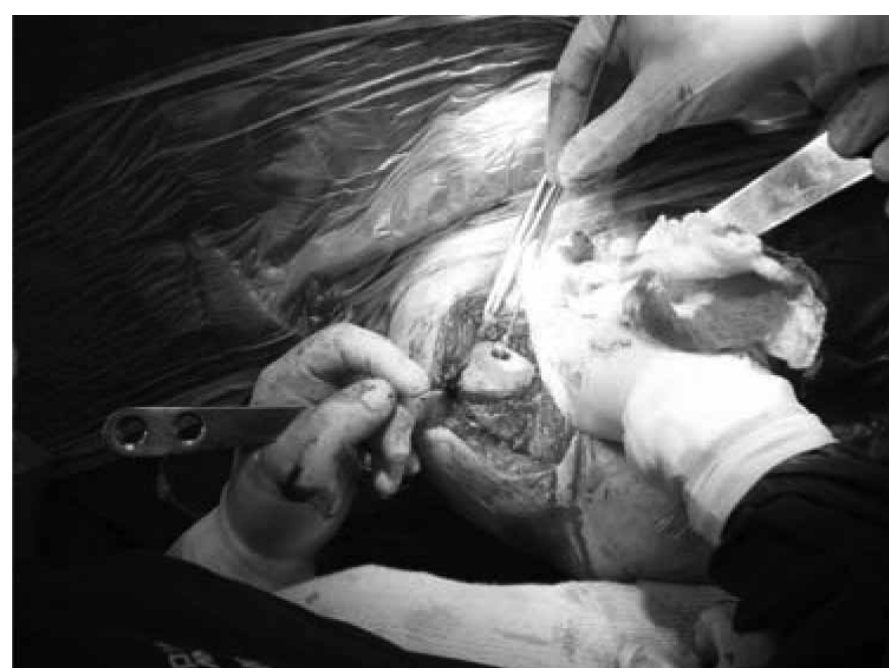

Figure 2 - Humeral head drilled after specific guidance.

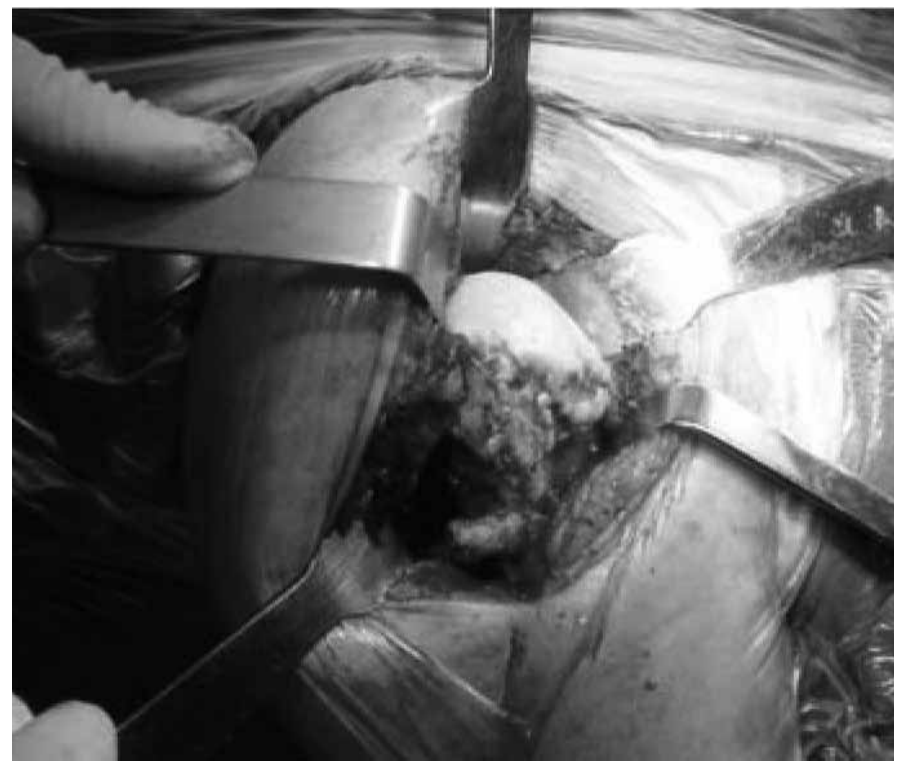

Figure 5 - Test piece for the final implant.

Rev Bras Ortop. 2011;46(3):288-92

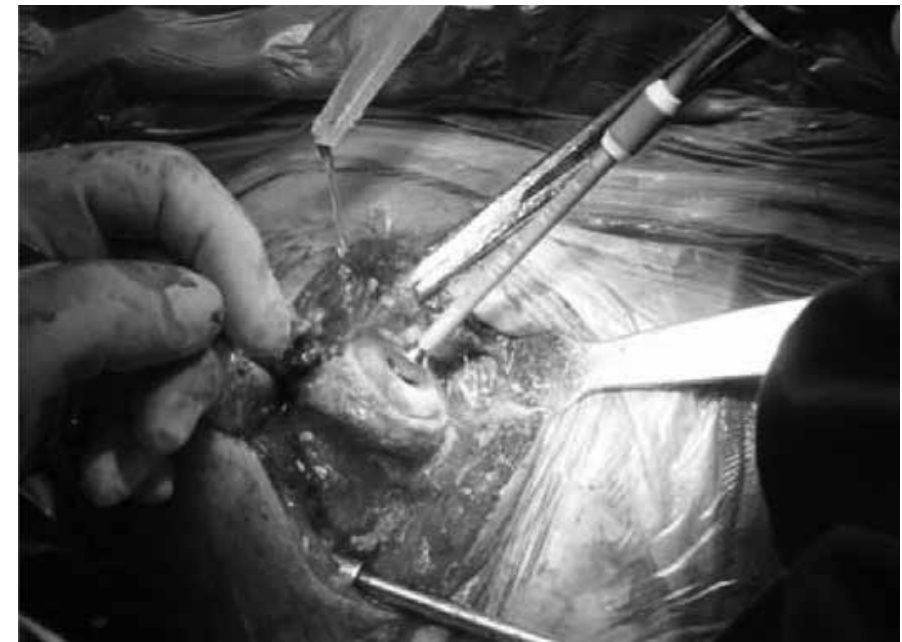

Figure 3 - Preparation of the humeral head using a specific circumferential rasp.

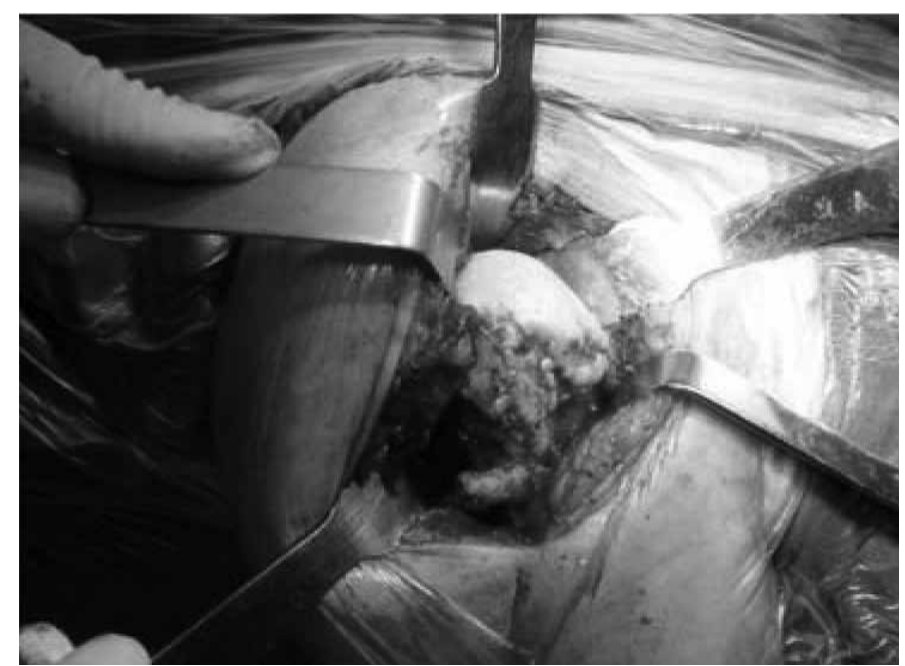

Figure 4 - Humeral head prepared with a threaded pin for the final implant.

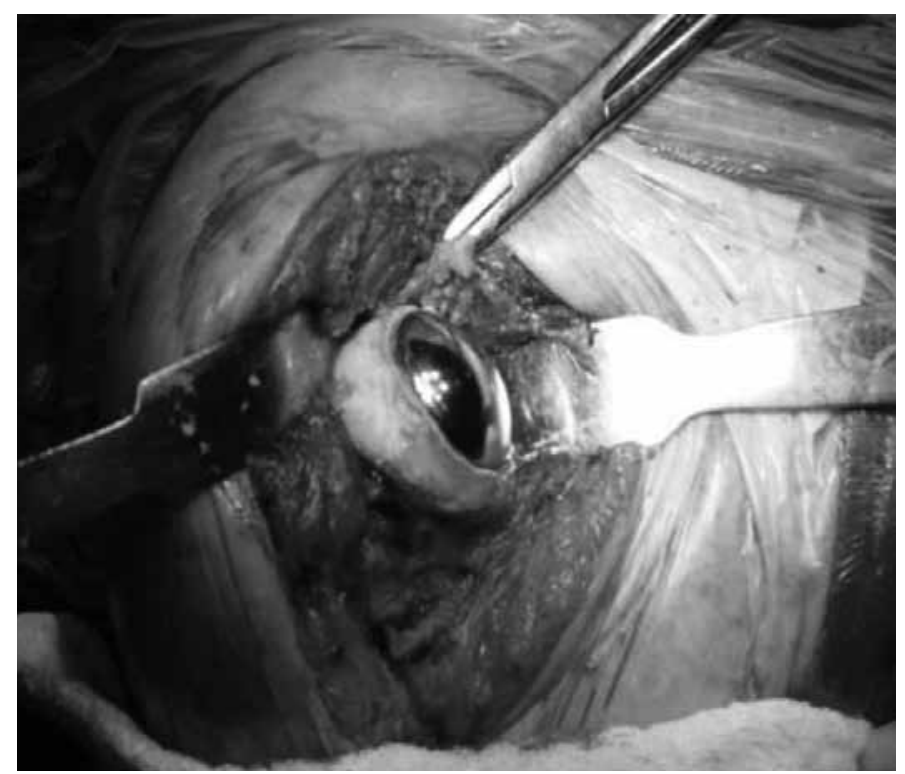

Figure 6 - Final implant of arthrosurface in position. 


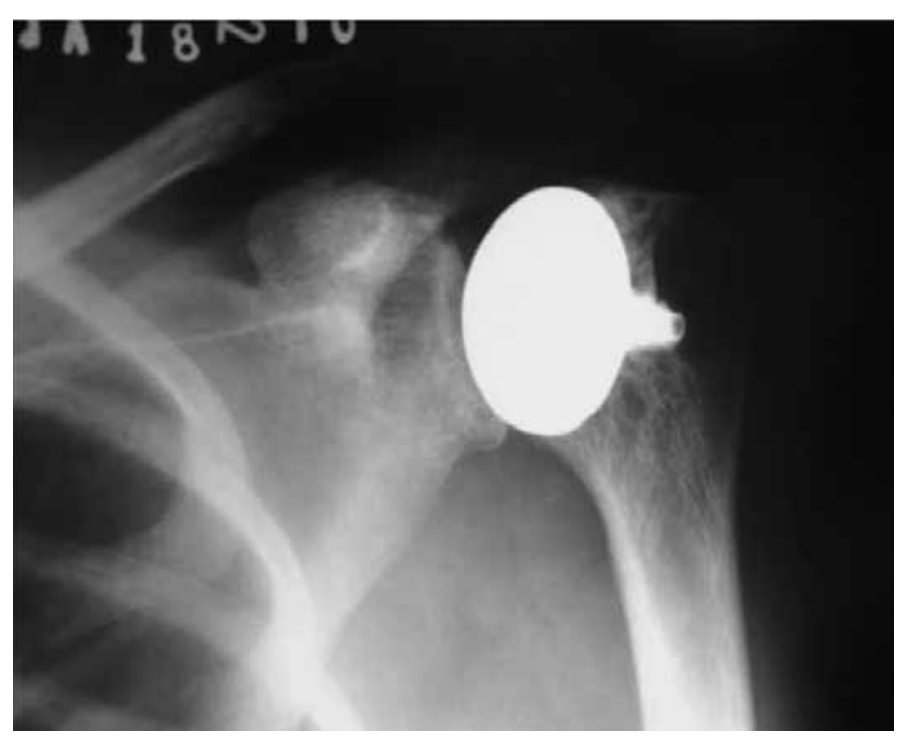

Figure 7 - Control X-ray image showing implant covering the entire compromised area of the humeral head.

\section{RESULTS}

With regard to the surgical findings, in order to effectively cover the lesions of the humeral head, $80 \%$ of the implants used in this study had a diameter of 35 $\mathrm{mm}$ and $20 \%$ had a diameter of $30 \mathrm{~mm}$. There were none with 25 or $40 \mathrm{~mm}$.

The postoperative radiographs after the revision showed solid fixation of the components without any sign of radiolucency or evidence of implant migration.

The mean postoperative follow-up was 17 months, with a range from six to 29 months (Table 1).

Using the assessment method of the UCLA scale (13), we observed good and excellent results in eight patients $(80 \%)$ and fair results in two patients(20\%), with mean scores of 30 and 25 points, respectively. However, the patients' degree of satisfaction was seen to be even better: a single patient presented only a moderate degree of satisfaction and four points on the analogue pain scale (Table 2).

\section{DISCUSSION}

Most present-day implants used in treating osteoarthrosis of the shoulder promote good results in terms of pain relief. However, regarding the range of motion, the results may be disappointing ${ }^{(14,15)}$. Through application of the HemiCAP-Arthrosurface ${ }^{\circledR}$ system, this disappointment was not seen in our study.

Warner et $\mathrm{al}^{(16)}$ showed that the glenoid was com-
Table 2 - Data on patients.

\begin{tabular}{c|c|c|c|c}
\hline $\begin{array}{c}\text { Patient } \\
\text { number }\end{array}$ & Cause/Origin & $\begin{array}{c}\text { UCLA } \\
\text { (postoperative) }\end{array}$ & $\begin{array}{c}\text { Postoperative } \\
\text { analogue } \\
\text { scale }\end{array}$ & $\begin{array}{c}\text { Degree of } \\
\text { satisfaction }\end{array}$ \\
\hline 1 & Osteoarthrosis & 25 & 2 & High \\
\hline 2 & Osteoarthrosis & 28 & 1 & High \\
\hline 3 & Osteoarthrosis & 31 & 1 & High \\
\hline 4 & Osteoarthrosis & 31 & 0 & High \\
\hline 5 & Osteoarthrosis & 25 & 4 & Moderate \\
\hline 6 & Osteoarthrosis & 30 & 2 & High \\
\hline 7 & Osteoarthrosis & 29 & 1 & High \\
\hline 8 & Osteoarthrosis & 28 & 2 & High \\
\hline 9 & Osteoarthrosis & 31 & 0 & High \\
\hline 10 & $\begin{array}{c}\text { Avascular } \\
\text { necrosis }\end{array}$ & 32 & 0 & High \\
\hline
\end{tabular}

Source: DOT-CATO

UCLA = University of California at Los Angeles - method for assessing postoperative results.

promised in all the patients who underwent conventional hemiarthroplasty with a mean follow-up of 43 months. In our postoperative follow-up, we did not observe any deleterious involvement of the glenoid.

Buchler e Farron $^{(17)}$ described the importance of anatomical reconstruction to restore physiological movement and the original muscle strength, and to limit the eccentric loading on the glenoid.

Many studies have described the complexity and variability of the geometry of the humeral head ${ }^{(18,19)}$.

The advantages of the HemiCAP-Arthrosurface ${ }^{\circledR}$ system over conventional arthroplasty on the shoulder are based on preservation of the bone stock of the humeral head and joint cartilage. Furthermore, the joint biomechanics are maintained, including joint height, angular inclination, soft-tissue tension and joint version. Complications relating to the humeral diaphysis and tuberosities are avoided with this type of system, given that these areas are not damaged during the procedures of this surgical technique. Burgess et $\mathrm{al}^{(20)}$ were very clear in affirming that, in comparison with conventional arthroplasty of the shoulder, surface arthroplasty presents a series of advantages: a) no osteotomy is performed; b) the bone resection needed is minimal; c) the duration of the operation is reduced; d) there is low incidence of periprosthetic fractures; e) conversion of the operation into total arthroplasty, if necessary, is easily done.

For most of the patients in this study $(90 \%)$, the HemiCAP-Arthrosurface ${ }^{\circledR}$ system was indicated for 
patients with a mild to moderate degree of primary osteoarthrosis of the shoulder. However, this system can also be used for treating avascular necrosis of the humeral head ${ }^{(21)}$.

\section{CONCLUSION}

Treatment of degenerative pathological conditions of the shoulder by means of the HemiCAP-Arthrosurface ${ }^{\circledR}$ system was shown to be a less aggressive surgical technique, with preservation of the bone stock. It was efficient in promoting pain relief, with correction of the lesion/deformity and recovery of the range of motion over a short space of time. With this technique, conversion to total arthroplasty of the shoulder is possible, with the major advantage that the bone stock is preserved.

This is a procedure with lower morbidity. It easy to apply after the technique has been mastered.

As seen, we observed very good postoperative results among our patients. However, longer-term follow-up and a greater number of patients are certainly necessary in order to corroborate our findings.

\section{REFERENCES}

1. NEER CS 2 nd. Articular replacement for the humeral head. J Bone Joint Surg Am. 1955;37-A(2):215-28.

2. Gartsman GM, Roddey TS, Hammerman SM. Shoulder arthroplasty with or without resurfacing of the glenoid in patients who have osteoarthritis. J Bone Joint Surg Am. 2000;82(1):26-34

3. Godenèche A, Boileau P, Favard L, Le Huec JC, Lévigne C, Nové-Josserand L, et al. Prosthetic replacement in the treatment of osteoarthritis of the shoulder: early results of 268 cases. J Shoulder Elbow Surg. 2002;11(1):11-8.

4. Iannotti JP, Norris TR. Influence of preoperative factors on outcome of shoulder arthroplasty for glenohumeral osteoarthritis. J Bone Joint Surg Am. 2003;85(2):251-8.

5. Rodosky MW, Bigliani LU. Indications for glenoid resurfacing in shoulder arthroplasty. J Shoulder Elbow Surg. 1996;5(3):231-48.

6. Radnay CS, Setter KJ, Chambers L, Levine WN, Bigliani LU, Ahmad CS. Total shoulder replacement compared with humeral head replacement for the treatment of primary glenohumeral osteoarthritis: a systematic review. J Shoulder Elbow Surg. 2007;16(4):396-402.

7. Levy O, Copeland SA. Cementless surface replacement arthroplasty of the shoulder. 5- to 10-year results with the Copeland mark-2 prosthesis. J Bone Joint Surg Br. 2001;83(2):213-21.

8. Copeland SA. Cementless total shoulder replacement. In: Post M, Morrey BF, Hawkins FJ, editors. Surgery of the shoulder. St Louis: Mosby Year Book: 1990. p. 289-97.

9. Jónsson E, Egund N, Kelly I, Rydholm U, Lidgren L. Cup arthroplasty of the rheumatoid shoulder. Acta Orthop Scand. 1986;57(6):542-6.

10. Rydholm U, Sjogen J. Surface replacement of the humeral head in the rheumatoid shoulder. J Shoulder Elbow Surg. 1993;2:286-95.
11. Murray DW, Carr AJ, Bulstrode C. Survival analysis of joint replacements. J Bone Joint Surg Br. 1993;75(5):697-704.

12. Neer CS 2nd, Watson KC, Stanton FJ. Recent experience in total shoulder replacement. J Bone Joint Surg Am. 1982;64(3):319-37.

13. Ellman H, Hanker G, Bayer M. Repair of the rotator cuff. End-result study of factors influencing reconstruction. J Bone Joint Surg Am. 1986;68(8):1136-44.

14. Fehringer EV, Kopjar B, Boorman RS, Churchill RS, Smith KL, Matsen FA 3rd. Characterizing the functional improvement after total shoulder arthroplasty for osteoarthritis. J Bone Joint Surg Am. 2002;84(8):1349-53.

15. Stewart MP, Kelly IG. Total shoulder replacement in rheumatoid disease: 7 - to 13-year follow-up of 37 joints. J Bone Joint Surg Br. 1997;79(1):68-72.

16. Parsons IM 4th, Millett PJ, Warner JJ. Glenoid wear after shoulder hemiarthroplasty: quantitative radiographic analysis. Clin Orthop Relat Res. 2004;(421):120-5..

17. Büchler P, Farron A. Benefits of an anatomical reconstruction of the humeral head during shoulder arthroplasty: a finite element analysis. Clin Biomech (Bristol, Avon). 2004;19(1):16-23.

18. Boileau P, Walch $G$. The three-dimensional geometry of the proximal humerus. Implications for surgical technique and prosthetic design. J Bone Joint Surg Br. 1997;79(5):857-65.

19. Jobe CM, lannotti JP. Limits imposed on glenohumeral motion by joint geometry. J Shoulder Elbow Surg. 1995;4(4):281-5.

20. Burgess DL, McGrath MS, Bonutti PM, Marker DR, Delanois RE, Mont MA. Shoulder resurfacing. J Bone Joint Surg Am. 2009;91(5):1228-38.

21. Uribe JW, Botto-van Bemden A. Partial humeral head resurfacing for osteonecrosis. J Shoulder Elbow Surg. 2009;18(5):711-6. 